\title{
Escribir extrañas atracciones: conversación sostenida con Adrian Heathfield ${ }^{1}$
}

Fecha de recepción: 10 de abril de 2018

Fecha de aprobación: 13 de septiembre de 2018

Adrian Heathfield es escritor, curador y creador de/sobre performance; dedicado a repensar por qué el performance importa a partir de la materia del performance. Heathfield ha trabajado con numerosos artistas y pensadores en colaboraciones críticas y creativas que incluyen diálogos filmicos, conferencias performáticas, dramaturgias, proyectos de escritura y talleres. Es profesor de Performance y Cultura visual en la Universidad de Roehampton, en Londres. Es autor de Out of Now, a monograph on the artist Tehching Hsieh, editor de Ally y Live: Art and Performance, asi como coeditor de Perform, Repeat, Record. Sus numerosos ensayos han sido traducidos a 10 idiomas.

Desarrolló el projecto de investigación-creación financiado por la Unión Europea Curating the Ephemeral (2014-2016) sobre arte inmaterial y prácticas museísticas. Fue codirector de Performance Matters, un proyecto de investigación sobre el valor cultural del performance financiado por el Consejo para la investigación en las Artes y Humanidades AHRC (2009-2013). Fue co-curador la franja de eventos de Cultura Viva del Tate Modern en Londres (2003), así como de otros performances y eventos duracionales en ciudades europeas durante los últimos 18 años.

1 La traducción de esta entrevista ha sido hecha por Juliana Borrero

Citar: Heathfield, A. \& Borrero, J. (enero-junio de 2019). Escribir extrañas atracciones: conversación sostenida con Adrian Heathfield. La Palabra, (34), 103-108. https://doi.org/10.19053/01218530.n34.2019.9531

\section{Adrian Heathfield}

Profesor de Performance y Cultura visual - University of Roehampton, Londres

http://www.adrianheathfield.net/

\section{Juliana Borrero}

Profesora Maestría en Literatura Universidad Pedagógica y Tecnológica de Colombia, Tunja julianaborrero@gmail.com. 
Conocí a Adrian Heathfield en Bogotá, en junio de 2014, en el Laboratorio de artistas Experimenta/ Sur III (http://www.experimentasur.com/encuentros/), una plataforma latinoamericana de artes vivas desarrollada en Mapa Teatro y patrocinada por el Goethe Institut. En este espacio, Heathfield ofreció un taller de Escritura performativa con el siguiente detonante: todo acto de escritura ya es performativo. En este taller, fui su traductora y también participante. Durante varias sesiones, desarrollamos ejercicios de atención al lenguaje, al cuerpo, al otro, cuidadosamente diseñados a partir de "restricciones creativas". Estas dolorosas rupturas, sacrificios arbitrarios, pérdidas sensitivas, rigurosamente cronometradas, donde el lenguaje está presente de diferentes maneras, son las reglas de juego del laboratorio, que permiten que el sentido se desdoble y el lenguaje se oxigene. Estas operaciones permiten recordar en carne propia la materialidad del lenguaje, la espacialidad del lenguaje, la relación entre pensamiento y lenguaje, lenguaje y memoria, lenguaje y movimiento, objeto y lenguaje, escritura y tiempo. Hacen perceptible la vulnerabilidad que está en todo acto de lenguaje, los modos de vínculo que se establecen con el otro a través de la voz y de la escritura, la angustia que acompaña toda entrega de lenguaje al otro; y, así mismo, hacen sentir que el lenguaje es, desde un principio, la primera restricción; desesperante y fascinante, digna de volver a ella una y otra vez.

La discusión sobre la performatividad del lenguaje, surge desde 1955. En la serie de conferencias Cómo hacer cosas con palabras, el lingüista J. L. Austin (1962) usa el término 'performativo' para indicar que los enunciados lingüísticos no solo describen el estado de las cosas o clarifican información, sino que también performan o realizan acciones. Esta comprensión del lenguaje como acción, ha resonado en campos como la Lingüística, los Estudios de Performance, el Teatro y la Filosofía, y cambia nuestra manera de comprender y construir significado. Esta discusión también ha cuestionado de manera importante las formas normalizadas de la escritura académica en las ciencias sociales.

Para Roland Pelias (2014), la escritura performativa "es poética, retórica y relacional” (p. 2). Della Pollock (1998) la describe así:

Lo que yo llamo escritura performativa es a la vez un medio y un efecto del conflicto. Es particular (y paradójicamente) 'efectiva'. Toma forma en el acto de hablar/escribir. Refleja, en sus propias formas, en la realización de su forma, en su performance de sí misma, una relación particular, histórica (agonística dialógica, erótica) entre sujetos autores, sujetos lectores, sujetos escritos/leídos [...] Dramatiza los límites del lenguaje (p. 83).

"Toma su pulso de la diferencia, más que de la identidad entre el símbolo lingüístico y la cosa que representa" (p. 84), "Sugiere un campo de posibilidad 'liminoide', un campo de formas mixtas hibridas que exceden las distinciones categóricas en su esfuerzo de hacer posible, de hacer presente la ausencia y sin embargo recuperar de la mimesis estructural, realista, la presencia para la poiesis" (p. 80). Sin embargo, "la escritura performativa no es un género ni una forma fija (como algunos textos pueden sugerir), sino una forma de describir algo que ya hace la buena escritura, al menos una parte de ella [...]" (p. 75)².

La performatividad del lenguaje pone sobre la mesa, preguntas como las siguientes: ¿qué significa hacer que la escritura performe o actúe como escritura? ¿Qué puede hacer la escritura? ¿En qué radica la fuerza de la escritura? ¿Por qué insistimos en escribir? ¿Qué es lo que hacemos cuando escribimos? Con esta

La traducción de las citas de Pollock es de Juliana Borrero. 
entrevista quisiera traer estos interrogantes al campo de la Literatura -y de la investigación-creación o investigación basada en artes en general- donde sabemos y no sabemos estas cosas, y donde muchas de estas implicaciones pueden ser exploradas. ¿Qué tipo de pistas puede ofrecer la escritura performativa para la exploración de la escritura, tanto creativa como académica? ¿Qué tipo de escritura acompaña la investigación-creación? ¿Qué caminos abre la atención al cuerpo, la materialidad del lenguaje y la escritura como performance para la Literatura y para las Artes?

\section{JB: ¿Qué entiendes por escritura performativa?}

AH: La escritura performativa es casi un género pero es también una dimensión que está en toda la buena escritura. Hay bastante literatura sobre este tipo de escritura, como Peggy Phellan con Unmarked (1993), que es una teoría inaugural de la escritura performativa; y el maravilloso ensayo sumativo de Della Pollock (1998). Con relación a la escritura que se hace en las Artes, mi punto de vista es muy sencillo: pienso en la escritura performativa como un acercamiento a la continuación de la fuerza de la obra, o de un asunto, solo que la continuación de su fuerza es su transformación, e implica escribir en un sentido distinto. Los significados y afectos de las obras de arte sobre las que puedo querer escribir, me perturban y me exceden. No puedo capturar ni contener su exceso, pero puedo hacer un frágil intento, y al hacerlo habré traducido su fuerza.

Hay ciertos asuntos implicados en esto. Uno de ellos puede ser la relación con lo sensible; repensar la relación entre los sentidos, el pensamiento y el lenguaje. Lo que, a su vez, implica interrogar al sujeto que escribe, que puede involucrar poner a prueba el propio contenido, algo que te despierta o te desafía, algo biográfico, o experiencial quizás. Pero, la escritura performativa no se queda en lo anecdótico, pues para honrar la fuerza de la obra o de un asunto, es necesario afinar la escucha de aquello que no permite ser conocido [unknowability], y así escribir de maneras que te deshacen como sujeto. Finalmente, diría que otra cosa que determina la escritura performativa para mí, es su fuerza promisoria, lo que tiene algo que ver con lo potencial y con un futuro; una forma de potenciar el tema y de crear nuevos futuros. Es un tipo de escritura que genera otras escrituras.

JB: Observándote a hablar en el taller de estos días, tengo la impresión de que te mueves entre planos muy distintos; entre la escritura, la teoría, casos de artistas específicos, lugares más autobiográficos o subjetivos, el procesamiento de la experiencia directa, de manera que estás constantemente saltando entre esferas muy distintas. Quería preguntarte cómo haces para desplazarte entre proyectos de escritura tan distintos. Y me doy cuenta de que también saltas dentro de un mismo proyecto. ¿Es doloroso, necesario, agotador ese saltar?

AH: Pienso que es, sobre todo, una necesidad. El pensamiento es así. Saltar entre planos es algo que ocurre en cualquier tipo de escritura. En algunos tipos de escritura, ese saltar es más implícito que explícito, menos visible formalmente, pero creo que tienes razón, es un método, tiene el estatus de un método para mí. De lo que se trata es de un esfuerzo por situarme en el lugar de encuentro entre diferentes elementos que siento que están relacionados, pero que no están conectados explícitamente o en discursos previos; así que yo [como sujeto que escribe] me convierto en el nexo por medio del cual estos elementos entran en diálogo, y eso tiene mucho que ver con la intuición, básicamente porque el método de relación entre planos es un método sensible, intuitivo. 
A menudo, lo que intento hacer es buscar atracciones extrañas entre elementos que siento que están relacionados, pero que no me queda claro cómo se relacionan. La escritura se convierte en una manera de interrogar la relación.

\section{JB: Así que definitivamente en la escritura ocurre algo que no estaba allí antes. Hay algo que se encuentra...}

AH: Uno escribe para descubrir lo que esa relación podría ser. Otro cosa implicada es que puede ser necesario hablar diferentes tipos de lenguajes; no me refiero solo al lenguaje verbal o a diferentes idiomas; sino a géneros y vocabularios muy distintos, para poder referirse a los diferentes planos, temáticas o zonas que tienen que ver con el asunto. Se trata de hacer un tipo de escritura que sea lugar de encuentro para diferentes tipos de voces. Lo que también viene de un interés por escribir desde más de una posición subjetiva, canalizando diversidad y contradicción. Así, el acto de escribir es un poco como una sesión de espiritismo, uno convoca las voces de otros y escribe a través de ellas, o ellas escriben a través de uno.

\section{JB: ¿Encuentras que este cambio de voces y estilos es agresivo con el lector? ¿Cambiar de voces es como ponerte en el lugar de los artistas sobre los que trabajas?}

AH: Pero no es exactamente en el lugar del artista, porque yo no puedo entrar en el lugar del artista, no importa cuánto lo intente. Lo que me interesa es lo que emana de un artista, que ellos mismos pueden no conocer o controlar. No siento que sea agresivo con el lector, me parece todo lo contrario. No es difícil de leer o de escuchar, pero puede requerir suspender las expectativas convencionales sobre lo que es un texto. Nos han enseñado a escribir en formas racionales, instrumentales y herméticas: se deben explicar todos los espacios entre los pensamientos y observaciones.

Nos han dicho que el trabajo de la oración es relacionarse con la anterior o servir de marco para la siguiente. No obstante, en la mejor escritura, esto casi nunca ocurre. Una oración es una oración y hay espacios productivos en las buenas oraciones. También hay espacios productivos entre las buenas oraciones. Con gusto, el lector hace el trabajo de pensar en la relación entre ellas. Así que, para mí este método es solo una forma más explícita e idiomática de trabajar con algo que ya está ocurriendo en toda buena escritura.

\section{JB: ¿Alguna vez te has cansado del lenguaje, de la escritura?}

AH: Creo que siempre estoy cansado del lenguaje. ¡El lenguaje es felizmente inútil! Es decir, en cierta manera, es completamente redundante. Yo empiezo a escribir desde la conciencia de la redundancia implícita de todo lenguaje. Y si empiezo desde ese lugar, entonces la escritura se vuelve interesante. Es por esta razón que, pienso que uno nunca está autorizado para escribir. Cuando me siento a escribir algo, aún no estoy autorizado para escribirlo, solo me autorizo al escribirlo. De manera que, en realidad nunca sé si voy a poder escribir lo que tengo que escribir. Parte de la buena escritura es estar consciente y sospechoso de la escritura pre-autorizada, resistirse a ella. Todos tenemos escritura pre-autorizada en nosotros, que es la que nos enseñaron a hacer, la articulación de esa voz en nuestra cabeza que sentimos como propia, que es como escribimos cuando no cuestionamos lo pre-autorizado. 
JB: Hoy, en el taller, decías que estabas intentando hacer que los bailarines no bailaran. Yo pensaba en los escritores. ¿Cómo deshabituar la escritura? ¡Cómo es de difícil, cuando uno ya ha encontrado una escritura poderosa, encontrarla de nuevo!...

AH: Esta tensión entre los hábitos y la deshabituación, o la automatización y desautomatización de la escritura, no tiene fin. Un buen escritor es una persona que sabe desautomatizar. Entendiendo que no se puede ser un desautomatizador automático... es difícil ser habitualmente bueno en deshabituarse, es un asunto de práctica. La verdadera pregunta es: ¿cómo me acerco a los límites de mi pensamiento, a los límites de mi práctica? ¿Cómo engañarse a sí mismo para salir de los patrones cómodos de pensamiento, los propios lugares de dependencia, las conclusiones familiares, la historia que uno se ha estado contando para mantenerse en un lugar seguro? ¿Cómo hacerse una pregunta en el límite? ¿Cómo aprender a suspender el límite: es decir, a desplazarlo cada vez más?

JB: Pero, también hay algo que permanece, un estilo o un método... ¿Hay algo que comienza a crecer, además de la desautomatización?

AH: Esta desautomatización no tiene solo que ver con soltar, deshacerse de elementos; también es una acumulación, de nuevas técnicas y versatilidades. Es decir, se aprende de la experiencia, al menos eso esperamos. Y por supuesto es imposible borrar el rastro de uno mismo en su escritura, uno siempre está allí en algún tipo de firma, aun cuando no lo podemos escuchar ni ver.

JB: Me pregunto cómo abrir en la escritura una atención al proceso, a la escritura como proceso, lo que tiene que ver con el tiempo, con la materialidad...

AH: La escritura procesual invoca otra temporalidad: tiene relación con lo sensible y con la creación de futuros... Estar presente ante las cosas, a medida que se desarrollan en el tiempo, implica atender a su emergencia sensorial en, alrededor y a través de uno. Esto activa una forma de compromiso material, carnal. Una atención a la inmanencia y el devenir.

Al hacer una escritura procesual, uno está escribiendo sobre algo que está incompleto, y que es evidentemente menos que el tiempo que se intenta contar o abarcar. El fracaso de la escritura de contener el tiempo del que habla, reconoce la posibilidad de otros tiempos dentro de ese tiempo, y así, crea nuevos futuros. Estas dos cualidades -el desdoblamiento sensorial y la inadecuación lingüística- determinan en buena parte cualquier forma de escritura procesual; por esto es bueno practicarla.

\section{JB: ¿La anécdota sería una manera de escribir el proceso de manera no prescriptiva?}

AH: Prefiero las "analectas", que son como pequeñas historias pero también filosofías mínimas, son como pequeños bocados filosóficos. El problema de las anécdotas es que, a menos que uno logre escribirlas muy bien, tienden a cerrarse en torno a la experiencia, y a constreñirse demasiado en torno al sujeto que escribe. A menos que uno logre escribirlas muy bien, resultan en un sujeto demasiado consolidado y cierran la narrativa. En la vida, las anécdotas son absolutamente vitales y una forma maravillosa de intercambiar la experiencia, pero en la escritura a menudo me encuentro leyendo la 
historia que el ser se ha contado a sí mismo una y otra vez, a menos que las anécdotas sean múltiples y estén en relación compleja unas con otras.

JB: Una última pregunta: ¿qué crees que la literatura puede aprender al entrar en contacto con el performance y las artes contemporáneas? ¿Qué necesita aprender la literatura?

AH: ¡Esa es una pregunta muy grande! Te doy una respuesta rápida: necesita aprender a acabar con el logo-centrismo, lo cual es un proceso sin fin para todos. Este es el problema más grande que tienen las formas institucionalizadas del estudio de la literatura, y es por eso que el teatro presenta un problema tan grande en esos contextos, porque se rehúsa a ser sometido. Hay muchos estudiosos de la literatura que están haciendo el trabajo de cambiar esto, pero no son la mayoría.

JB: Entonces, es un problema que tiene que ver con la manera en que se lee y se escribe sobre la literatura en la academia; ¿con la manera como se comprende el trabajo literario?

AH: Es un problema con la tiranía de la Palabra... Y no solo estoy pensando en los cuerpos, sino en la relación entre cuerpos y otras cosas: objetos, animales, espíritus. La palabra nunca es una cosa en sí misma: esa es su felicidad, así como su horror.

JB: Gracias, ese es un final perfecto.

Mapa Teatro, junio 2014

\section{Referencias}

Austin, J. L. ([1962] 1975). How to do things with words. Cambridge, Massachusetts: Harvard University Press.

Pelias, R. J. (2014). Performance: an alphabet of performative writing. New York: Routledge.

Phelan, P. (1993). Unmarked: the politics of performance. New York: Routledge.

Pollock, D. (1998). Performing writing. En P. Phelan \& J. Lane, The ends of performance (pp. 73-103). New York: New York University Press. 